\title{
Avaliação em larga escala e currículo: relações entre o PISA e a BNCC
}

Emilly Gonzales Jolandek

Ana Lúcia Pereira

Luiz Otavio Rodrigues Mendes

\section{Resumo}

O presente artigo tem como objetivo fazer um estudo comparativo entre os documentos oficiais do PISA e da BNCC de Matemática, evidenciando e discutindo alguns conceitos e definições como processos, letramento, habilidades e conteúdos estruturantes, abordados nos documentos. Primeiramente apresentamos algumas reflexões sobre como as avaliações externas e em larga escala refletem no processo de ensino e aprendizagem em Matemática, traçamos também um breve histórico sobre o sistema educacional brasileiro até a implantação da Base Nacional Comum Curricular (BNCC), sendo abordado também um breve histórico sobre avaliação em larga escala no Brasil, tendo por enfoque o PISA. A pesquisa é de abordagem qualitativa, sendo utilizada a análise documental para fazer as relações entre os documentos oficiais do PISA e da BNCC, verificamos especificamente a parte de Matemática de ambos os documentos. Ficam ainda alguns questionamentos em relação aos documentos, entretanto foi possível evidenciar a relação e a influência que as avaliações externas e em larga escala ocasionam nas políticas públicas educacionais, em especial a estrutura da nova BNCC.

Palavras-chave: Avaliação em Larga Escala, Currículo, PISA, BNCC, Matemática. 


\title{
Large scale and curriculum evaluation: relations between PISA and BNCC
}

\author{
Emilly Gonzales Jolandek \\ Ana Lúcia Pereira \\ Luiz Otavio Rodrigues Mendes
}

\section{Abstract}

The present work had the objective of comparing the official documents of PISA and BNCC of Mathematics, evidencing and discussing the definitions, processes, literacy, skills and structuring contents, addressed in the documents. Thus we first present how external and large scale evaluations reflect in the process of teaching and learning in Mathematics, we also draw a brief history about the Brazilian educational system up to the implementation of the National Curricular Common Base (BNCC). A brief history of large scale evaluation in Brazil was also discussed, focusing on PISA. The research is qualitative approach, using documentary analysis to make the relationships between official PISA and BNCC documents, we specifically checked the Mathematics part of both documents. There are still some questions regarding the documents, however it was possible to highlight the relationship and the influence that external and large-scale evaluations have on public educational policies, especially the structure of the new BNCC.

Keywords: Evaluation in Large Scale, Curriculum, PISA, BNCC, Mathematics 


\section{Introdução}

Já faz um tempo que a disciplina de Matemática tem sido alvo nas avaliações em larga escala em níveis nacionais e internacionais. A participação da disciplina nessas avaliações acaba também afetando o seu ensino, pois além de ser sempre analisado, aparentemente sofre com os impactos dos resultados das avaliações em larga escala, aplicadas na Educação Básica. A média das avaliações em larga escala aplicadas no Brasil, são consideravelmente baixas compara a outros países, especificamente em Matemática.

As avaliações em larga escala, têm por objetivo diagnosticar o desempenho dos estudantes na Educação Básica, medindo também a qualidade dos sistemas de ensino. Dentro das principais avaliações em larga escala, nacionais e internacionais, aplicadas na Educação Básica no Brasil temos: Sistema de Avaliação da Educação Básica (SAEB) e o Programa Internacional de Avaliação de Estudantes (PISA).

No Ensino Fundamental II, a média brasileira em Matemática no SAEB (2015) foi de 256 pontos $^{34}$, e no PISA (2015) a média foi de 377 pontos $^{35}$. Vale destacar que cada avaliação em larga escala, nacional e internacional, possui amostras diferenciadas, pois são aplicadas para anos/séries diferentes. A Matemática dentro dos rankings internacionais principalmente no PISA, é apresentada em um nível muito baixo comparada à média de outros países, que foi de 490 pontos, o que também não se difere no desempenho do SAEB que aparentemente é baixo.

A partir desse contexto, a presente investigação tem como foco o estudo as avaliações realizadas pelo PISA, que é coordenada pela Organização para a Cooperação e Desenvolvimento Econômico (OCDE), engloba um conjunto de países, e busca desenvolver melhores políticas públicas, para melhorar a qualidade de vida (BRASIL, 2015). Segundo a OCDE embora o PISA não tenha como objetivo desenvolver testes diretamente atrelados com o currículo escolar, de certa forma, as avaliações em larga escala acabam influenciando nos sistemas educacionais, nas políticas públicas e nos currículos dos países que participam da avaliação. Podemos citar como exemplo a recente reforma que ocorreu no sistema educacional brasileiro, com a criação da nova Base Nacional Comum Curricular (BNCC), que propõe a garantia de aprendizagens essenciais que alunos da Educação Básica deverão adquirir e desenvolver ao longo dos anos de estudo. A reforma trouxe algumas mudanças para o ensino, em especial o de Matemática, que já apresenta condições, definições e processos relacionados ao documento do PISA.

\footnotetext{
$34 \quad$ Informação obtida em: http://download.inep.gov.br/educacao_basica/saeb/aneb_anresc/resultados/resumo_dos_resultados_saeb_201 5.pdf

35http://download.inep.gov.br/acoes_internacionais/pisa/documentos/2016/pisa_brasil_2015_apresentacao.pd $\mathrm{f}$ 
Por hipótese tomamos que o fraco desempenho do Brasil nos rankings no PISA influenciou na reformulação da nova BNCC, tendo por finalidade que professores possam trabalhar conteúdos, processos e habilidades que estejam interligados com as avaliações em larga escala, notavelmente o PISA. O interesse na construção da nova Base, ultrapassa os muros da educação e envolvem outros setores como o empresarial, industrial e o político, e as esferas públicas e privadas. Acreditamos que essa influência pode ser observada a partir da análise dos relatórios do PISA e do documento da BNCC. Assim sendo, buscamos através deste artigo responder a seguinte questão: Qual a influência das avaliações em larga escala para a construção da Base Nacional Comum Curricular (BNCC)? E como os conteúdos matemáticos estão evidenciados na BNCC e nos documentos de avaliações em larga escala?

Portanto para responder esses questionamentos, pretendemos realizar um estudo comparativo entre os documentos oficiais do PISA e da BNCC de Matemática, evidenciando e discutindo as definições, processos, letramento, habilidades e conteúdos estruturantes abordados nos documentos.

Como opção de processo de escrita, os pesquisadores organizaram o artigo da seguinte forma: primeiro abordaremos o que é avaliação em larga escala, quando foi implantada no Brasil e quais os reflexos no processo de ensino-aprendizagem para professores e alunos na disciplina de Matemática. No segundo momento apresentaremos um breve histórico sobre a BNCC e o PISA. Em seguida, apresentaremos um estudo comparativo entre a BNCC e o PISA, buscando assim responder à questão norteadora, se existe influência do PISA na estruturação/reformulação do sistema educacional brasileiro e como os conteúdos matemáticos estão evidenciados nos documentos do sistema educacional brasileiro e nos documentos do PISA. Por fim, apresentamos as considerações finais passíveis de serem suscitadas a partir do estudo.

\section{Matemática e avaliação em larga escala: reflexos no ensino e aprendizagem}

Existem muitos desafios no campo da Matemática, principalmente nos processos de ensino e aprendizagem. A forma de abordagem dos conteúdos matemáticos ainda é tradicional e muitas vezes se apresenta sem bases históricas ou epistemológicas, tornando o seu ensino e aprendizagem pouco estimulantes e bastante formal. Poucas vezes ocorrem articulações e contextualizações dos conteúdos ensinados com o mundo real, mesmo quando há articulações o que prevalece no ensino são as técnicas de resoluções e memorização, que o aluno deve adquirir ao longo do período escolar.

Dessa forma, a aprendizagem do aluno acaba ficando limitada na maior parte dos conceitos matemáticos, e este na maioria das vezes acaba reproduzindo, modelos e fórmulas (UNESCO, 2016). A aprendizagem do indivíduo só ocorre quando há sentido e significado no 
que está aprendendo, a abstração presente na Matemática e a falta de contextualização presente no ensino desta disciplina, dificulta a aprendizagem do sujeito. Consequentemente a aprendizagem da Matemática é avaliada pelo senso comum como um estudo exclusivamente para poucos, é provável que a sociedade chegue a essa conclusão por conta da dificuldade que encontraram quando cursaram a disciplina e também por conta dos resultados de avaliações externas e em larga escala que aparece em noticiários, onde o ensino da Matemática brasileiro aparece comparado com outros países. É lamentável avaliar a aprendizagem matemática desta maneira, para Buriasco e Soares (2012) apud Cola (2015),

\begin{abstract}
A avaliação do desempenho dos alunos em matemática, portanto, deve ir muito além da apreciação de sua capacidade de memorização de símbolos e da reprodução de técnicas. Deve aferir sua capacidade de encontrar padrões, buscar regularidades, ler tabelas e gráficos, relacionar dados, montar esquemas, elaborar procedimentos. Considera-se que a documentação e a análise constante da produção do aluno durante seu processo de aprender e demonstrar o que já sabe ajudam, e muito, o professor nas escolhas, no planejamento, na realização e na avaliação de práticas (BURIASCO e SOARES, 2012, p. 111).
\end{abstract}

A Matemática permeia as atividades humanas de modo geral, mas existem obstáculos e barreiras que afetam a educação e sua forma de ser avaliada. Esses obstáculos constituídos pela sociedade, de que a matemática é uma ciência para poucos, dificulta o ensino de uma Educação Matemática de qualidade e para todos (UNESCO, 2015). Para a Organização das Nações Unidas para a Educação, a Ciência e a Cultura (UNESCO) e "A avaliação tem um papel crucial na implementação e na generalização bem-sucedida da educação matemática de qualidade para todos" (UNESCO, 2016, p. 26).

Para Cola (2015) qualquer modelo de avaliação tem por finalidade fornecer informações que auxiliem e norteiem tomadas de decisões, reflexões e resoluções de problemas. "No âmbito dos processos de ensino e aprendizagem da Matemática, essa avaliação precisa incluir dados a respeito das dificuldades presentes nas atividades dos alunos e também fornecer subsídios para a reorientação da prática escolar" (p. 34).

Dentro das modalidades de avaliação se destaca as avaliações em larga escala ou externas, essas avaliações tanto nacionais quanto internacionais são aplicadas em busca da melhoria na qualidade de ensino, com a "expectativa de obter informação confiável acerca do que os alunos sabem, assim monitorar o desempenho dos alunos e os respectivos sistemas" (FERNANDES, 2009 p. 111-112). No Brasil, as avaliações em larga escala surge da insatisfação com os sistemas educacionais, é recente esse sistema de avaliação, elas começam a ser aplicadas com maior ênfase a partir do ano 1990, entretanto a preocupação com o sistema educacional e a forma de avaliá-lo, surge a partir dos anos de 1970, sendo aplicados testes a partir de 1980, trazendo assim reflexos para o ensino, ora positivos, ora negativos.(GATTI, ISSN 2526-2882 
2014).

Em Matemática essas avaliações têm mostrado o desempenho da aprendizagem dos alunos ao final de cada ciclo da Educação Básica, entretanto os resultados não têm sido o que se almeja. Dentro dos reflexos, efeitos ou impactos que esses exames podem causar no processo de ensino e aprendizagem, tanto em Matemática quanto em outras disciplinas, Fernandes (2009, p.121) destaca alguns níveis de impactos:

a) na vida pessoal, social e acadêmica dos alunos;

b) nas formas como as escolas e os professores se organizam e desenvolvem o currículo;

c) naquilo que é ensinado e como é ensinado;

d) naquilo que é avaliado e como é avaliado;

e) na credibilidade social dos sistemas educativos.

Outro efeito, das avaliações em larga escala é o uso dos rankings, Fernandes (2009) destaca efeitos maléficos causados pelos rankings, escolas acabam aderindo estratégias e metodologias para estarem nas primeiras colocações. Isso foge do objetivo das avaliações em larga escala que não é de classificar, mas de melhorar o ensino (COLA, 2015). Consequentemente esses efeitos refletem na prática docente e também no aprendizado dos educandos.

A UNESCO (2016) destaca que a avaliação é necessária para o ensino da matemática bem como nas demais áreas, em sua dimensão formativa e somativa, e, deve "conduzir as aprendizagens, e avaliar a distância entre o currículo desejado e o currículo alcançado. Ela deve saber adequar as dimensões internas e externas, qualitativas e quantitativas, e se fundamentar nas metodologias apropriadas (p. 125)", e estar ligada ao processo de ensino e aprendizagem.

\section{Currículo e avaliação em larga escala}

Nesta seção traremos um breve histórico sobre currículo no sistema educacional brasileiro, desde os primeiros documentos até a implementação da nova Base Nacional Comum Curricular (BNCC), em seguida será apresentado o histórico das avaliações em larga escala aplicadas no Brasil com enfoque no PISA. Essa breve explanação sobre a nova BNCC e sobre o PISA, auxiliará para o estudo feito na seção cinco, onde será abordado relações entre os dois documentos.

\section{Estruturação da Educação brasileira e seus currículos}

A Educação no Brasil começou desde que ocorreu sua colonização por meio dos jesuítas. A cada período da história ocorreu mudanças no sistema educacional e a partir da proclamação da República foram promulgadas constituições que de certa forma, apresentavam alguns indícios em priorizar o ensino nas escolas públicas. A partir de 1931 foram criadas 
algumas leis que organizam o ensino secundário e as universidades, buscando pelo menos no papel, colocar a Educação como um direito de todos. Entretanto, entre criar uma lei e fazer com ela saia do papel, existem uma longa distância, e por isso, ocorreu rupturas no governo e retrocessos na Educação, e as transformações significativas na educação ocorre somente a partir de 1945. Com as mudanças, o ensino primário se torna obrigatório, e em 1948 ocorre a aprovação da Lei de diretrizes e Bases (LDB), mas foram apenas iniciativas de discussões, a educação teve ainda suas idas e vindas, ora era priorizada, ora não.

Em 1961 despontou uma esperança com a criação do Plano Nacional de Educação (PNE) e o Programa Nacional de Alfabetização, mas com o golpe militar (1964 - 1985) o cenário do sistema educacional brasileiro, muda novamente. Somente em 1971 se constitui a nova LDB (Lei no 5.692 de 11 de agosto de 1971), essa reforma propunha que a educação primária, hoje Ensino Fundamental duraria oito anos e o ensino de $2^{\circ}$ grau, hoje Ensino Médio passou a ser profissionalizante, mas ainda estava longe de se garantir a educação como um direito de todos. Dezessete anos depois, “[...] a partir da Constituição Federal (1988) que o país dá ênfase a uma política pública de caráter universal e a educação passa a ser concebida como um direito social de todos os indivíduos e dever do Estado (SILVA, 2013, p. 25). Essas leis servem de orientação para o sistema educacional brasileiro até hoje. A LDB em 1996 (Lei no 9.394 de 20 de dezembro de 1996) foi atualizada e, é utilizada até os dias atuais (SOUZA, 2016).

A Lei de Diretrizes e Bases da Educação contribuiu para o desenvolvimento educacional brasileira. Para Verde (2015, p. 81) a LDB são “verdadeiras diretrizes de como o currículo dos sistemas de ensino devem ser normatizados, de forma a constituírem um conjunto nacional”. Pode-se levar em conta que a LDB transformou o cenário educacional, abriu espaço consolidando medidas que ampliaram e melhoraram a educação (SOARES; BERNADO,2016). A partir da criação dessas Diretrizes, foi criado também o Parâmetros Curriculares Nacionais (PCN) que busca uma melhoria da qualidade na educação abordando aspectos como investimentos na formação de professores e recursos que auxiliem no processo de ensino e aprendizagem (BRASIL, 1997). Foi também atualizado o Plano Nacional de Educação (PNE), esse plano define metas e objetivos de aprendizagem a serem alcançados a cada 10 anos. O último PNE é constituído pela Lei ${ }^{\circ}$. 13.005 de 25 de junho de 2014, essa atualização do PNE apresenta as metas a serem atingidas do decênio de 2014 a 2024.

Os principais documentos aqui citados, entre outros, são a base para a construção do currículo do sistema educacional brasileiro. O artigo 26 da LDB (1996, p. 16) institui que "Os currículos do ensino fundamental e médio devem ter uma base nacional comum, a ser complementada, em cada sistema de ensino e estabelecimento escolar, por uma parte diversificada, exigida pelas características regionais e locais da sociedade, da cultura, da economia e da clientela”. Tendo em vista que a LDB já propunha uma Base Nacional Comum, 
em 2014 uma reformulação na educação começa a ser discutida para a criação de uma Base Nacional Comum Curricular (BNCC), tendo em vista contribuir com algumas estratégias propostas na Lei ${ }^{0}$. 13.005/2014 do Plano Nacional de Educação. Embora o MEC destaque que a elaboração da nova BNCC foi amplamente apresentada publicamente para opiniões, discussões e críticas da sociedade, vários movimentos destacam que esse processo não ocorreu de forma tão democrática (LINO, 2017; CNTE, 2017; GABRIEL et al., no prelo). Em meio a uma crise política, após discussões e reformulações, em dezembro de 2017 foi aprovada a implantação da nova BNCC (AGUIAR, 2018). Para Perez (2018) a BNCC,

[...] propõe-se a definir o conjunto orgânico e progressivo de aprendizagens essenciais que crianças, jovens e adultos devem desenvolver ao longo das etapas da Educação Básica. Estabelece de maneira minuciosa conhecimentos, competências e habilidades como direitos a serem aprendidos e desenvolvidos durante a escolaridade básica. A BNCC foi elaborada para assegurar a efetivação dos direitos de aprendizagem e desenvolvimento (PEREZ, 2018, p. 21).

O autor ainda aponta que os direitos de aprendizagem que a BNCC apresenta, se resume em:

10 competências gerais; 117 objetivos de aprendizagem e desenvolvimento; 35 competências específicas de áreas; 49 competências específicas de componentes curriculares; 1.303 habilidades, agrupadas em 81 conjuntos. No total, são 1.514 enunciados sobre aprendizagem e desenvolvimento! (PEREZ, 2018, p. 56).

A reformulação/construção do currículo, o seja na nova BNCC, trouxe mudanças para a Educação nacional, seguida de muitas críticas. Ela passa a ser uma referência obrigatória na Educação Básica, tanto em elaboração de currículos, como de materiais didáticos, formação de professores e elaboração de avaliações em larga escala nacionais (PEREZ, 2018)

\section{Avaliações em larga escala no Brasil}

Relatos históricos apontam que desde 1920 as avaliações em larga escala já eram realizadas no Brasil por influências americanas (ZANARDINI, 2008). Outros aportes teóricos da literatura mostram que a partir de 1960 com a Fundação Getúlio Vargas através do Centro de Estudos de Testes e Pesquisas Psicológicas (CETPP), nesse período o CETPP aplicou provas objetivas de todas as disciplinas e questionários socioeconômicos, para as últimas séries do Ensino Médio. Essa iniciativa de medir aprendizagem com a relação socioeconômica dos alunos pode ser considerada ligada a avaliação em larga escala (GATTI, 2014). Ainda segundo Gatti (2014) em 1970 o Programa de Estudos Conjuntos de Integração Econômica LatinoAmericana (ECIEL), realizou uma avaliação no Brasil e em outros países da América Latina, sobre o rendimento escolar. No decorrer das décadas de 70 e 80 ainda tiveram outros tipos de avaliações e exames aplicados nos Estados e municípios do país, uma delas foi o EDURURAL desenvolvido em todos os estados do Nordeste brasileiro durando de 1981 a 1986.

Nacionalmente somente a partir da Constituição de 1988, é que houve uma ISSN 2526-2882 
preocupação com o sistema de avaliação havendo a necessidade de verificar o desemprenho da aprendizagem dos alunos e a qualidade da Educação Básica. Neste mesmo ano o Ministério da Educação (MEC) realiza uma aplicação experimental do Sistema Nacional de Avaliação do Ensino Público (SAEP), sendo aplicado a primeira etapa em 1990, a partir dessa década as avaliações externas e em larga escala começam a se destacar. Também em 1990 foi instituído o Sistema de Avaliação da Educação Básica (SAEB) que tem por objetivo "realizar um diagnóstico da educação básica brasileira e de alguns fatores que possam interferir no desempenho do estudante, fornecendo um indicativo sobre a qualidade do ensino ofertado" (BRASIL, 2017a, p. 1). Em 1993 o MEC coloca em ação a aplicação do SAEB, a prova é aplicada a cada dois anos para o final de cada ciclo da Educação Básica, hoje o SAEB é composto por três avaliações em larga escala: i)Avaliação Nacional da Educação Básica (ANEB); ii) Avaliação Nacional do Rendimento Escolar (ANRESC), conhecida como Prova Brasil e; iii) Avaliação Nacional da Alfabetização (ANA).

Mas as avaliações externas e em larga escala aplicadas no Brasil não são apenas as nacionais propostas pelo Ministério da Educação (MEC), em 1997 a Organização para a Cooperação e Desenvolvimento Econômico (OCDE) lançou o Programa Internacional de Avaliação de Estudantes (PISA), entretanto, somente no ano de 2000 foi feita a primeira aplicação no Brasil. O PISA avalia alunos com 15 anos e dois meses e 16 anos e 3 meses no final da educação obrigatória, ou seja, da Educação Básica. É realizada a cada três anos e foca em três áreas: Ciências, Leitura e Matemática. Além da prova é aplicado questionários para os estudantes, professores, gestores da escola e pais. O PISA tem por objetivo,

[...] produzir indicadores que contribuam para a discussão da qualidade da educação nos países participantes, de modo a subsidiar políticas de melhoria do ensino básico. A avaliação procura verificar até que ponto as escolas de cada país participante estão preparando seus jovens para exercer o papel de cidadãos na sociedade contemporânea (BRASIL, 2015, p.1).

Para Wilkins (2013, p.50) a "visão global do PISA é justamente preparar os jovens, desenvolvendo suas competências e habilidades para a vida real, e visa-se a adequação das metas e objetivos do próprio currículo para aquilo que os estudantes conseguem fazer com o conhecimento adquirido na escola”. Em Matemática que é nosso foco nesse artigo, o PISA (2015) destaca como habilidades, que o aluno deve saber ao final da Educação Básica: processos matemáticos, letramento matemático, contextualização da Matemática com a vida real e a matematização. Sendo assim, na seção seguinte será exposto os aportes metodológicos e a estrutura de como será feito a comparação entre os documentos do PISA e da BNCC. Na seção 5 deste artigo traremos as definições para os elementos e competências matemáticas abordados pelo PISA. 


\section{Metodologia}

$\mathrm{Na}$ presente pesquisa adotamos como procedimentos metodológicos a pesquisa documental orientado pela pesquisa bibliográfica (BOGDAN; BIKLEN, 1994). Por meio desses métodos pretendemos responder a problemática desta pesquisa e cumprir com o objetivo proposto inicialmente, ou seja, comparar os documentos oficiais do PISA e da BNCC de Matemática, evidenciando e discutindo as definições, processos, letramento, habilidades e conteúdos estruturantes abordados nos documentos.

A pesquisa documental "vale-se de documentos originais, que ainda não receberam tratamento analítico por nenhum autor. [...] é uma das técnicas decisivas para a pesquisa em ciências sociais e humanas" (HELDER, 2006, p. 1-2 apud SÁ-SILVA, et. al 2009, p.3). Esse tipo de pesquisa "recorre a fontes mais diversificadas e dispersas, sem tratamento analítico, tais como: tabelas estatísticas, jornais, revistas, relatórios, documentos oficiais, cartas, filmes, fotografias, pinturas, tapeçarias, relatórios de empresas, vídeos de programas de televisão, etc.” (FONSECA, 2002, p. 32). Já a pesquisa bibliográfica que utilizamos como orientada da documental, segundo Gil (2002, p. 44) "é desenvolvida com base em material já elaborado, constituído principalmente de livros e artigos científicos".

Sendo assim para o desenvolvimento das reflexões e discussões apontadas nesse artigo, foi analisado o relatório do PISA (2015), especificamente as seções i) Capítulo 1. Introdução, ii) Capítulo 2. Participação do Brasil no PISA e iii) Capítulo 5. A avaliação de Matemática no Pisa 2015. Escolhemos o relatório do PISA 2015, por ser o mais atual até o presente momento (Julho/2018). Também analisamos a BNCC versão final do Ensino Fundamental, em especial o i) Capítulo 1. Introdução, ii) Capítulo 2. Estrutura da BNCC e iii) Capítulo 4, seção 4.2 A área de Matemática.

Através da análise dos dois documentos apresentaremos na próxima seção a relação entre eles, evidenciando as definições de processos matemáticos, letramento matemático, habilidades e conteúdos estruturantes, como também as definições dos documentos, objetivo geral e objetivo específico em Matemática, abordados.

\section{Resultados: Relações entre a BNCC e o PISA}

Muitos estudos têm apontado a forte influência das avaliações externas e em larga escala nas políticas públicas educacionais e na restruturação das mesmas (BAUER, et. al, 2015; HORTA NETO, 2013; MAINARDES, 2013, STECHER, 2002; VERDE, 2015). Já faz algum tempo que esse tipo de avaliação tem influenciado não só na construção dos currículos, mas também diretamente nos conteúdos trabalhados na sala de aula, um exemplo não muito distante são os vestibulares que influenciam no que é estudado no Ensino Médio (ABRALE, 2017). Essa influência também pode ser observada na construção da nova BNCC de 
Matemática do Ensino Fundamental, onde a utilização das avaliações em larga escala, como o PISA, aparece na sua estruturação. Segundo Antunes (2017, p.1) "os dados do PISA servem para a construção das políticas públicas na área educacional, procurando afinar a formação dos jovens em consonância com o que se espera deles na vida produtiva e social”.

No estudo realizado entre os documentos do PISA e da nova BNCC de Matemática, foi possível perceber várias relações entre eles. Na tabela 1 a seguir, traçamos as definições, objetivo geral e objetivo específico para Matemática a fim de conhecermos melhor os documentos.

Quadro 1 - Definições e objetivos PISA e BNCC

\begin{tabular}{|c|c|c|}
\hline & PISA & BNCC \\
\hline Definição & $\begin{array}{l}\text { Coordenado pela Organização para a } \\
\text { Cooperação e Desenvolvimento Econômico } \\
\text { (OCDE), o Programa Internacional de } \\
\text { Avaliação de Estudantes (PISA) é uma } \\
\text { avaliação externa que avalia o que alunos de } \\
15 \text { anos, no final da educação obrigatória, } \\
\text { adquiriram em relação a conhecimentos e } \\
\text { habilidades essenciais para a completa } \\
\text { participação na sociedade moderna. O PISA } \\
\text { faz parte de um conjunto de avaliações e } \\
\text { exames nacionais e internacionais } \\
\text { coordenados pela Diretoria de Avaliação da } \\
\text { Educação Básica (DAEB), do Instituto } \\
\text { Nacional de Estudos e Pesquisas } \\
\text { Educacionais Anísio Teixeira (INEP). (p 18.) }\end{array}$ & $\begin{array}{l}\text { A Base Nacional Comum Curricular (BNCC) } \\
\text { é um documento de caráter normativo que } \\
\text { define o conjunto orgânico e progressivo de } \\
\text { aprendizagens essenciais que todos os alunos } \\
\text { devem desenvolver ao longo das etapas e } \\
\text { modalidades da Educação Básica, de modo a } \\
\text { que tenham assegurados seus direitos de } \\
\text { aprendizagem e desenvolvimento, em } \\
\text { conformidade com o que preceitua o Plano } \\
\text { Nacional de Educação (PNE). (BNCC, p. } 7 \text { ) }\end{array}$ \\
\hline Objetivo geral & $\begin{array}{l}\text { Tem por objetivo o desenvolvimento de um } \\
\text { corpo de informações para o monitoramento } \\
\text { de conhecimentos e habilidades dos } \\
\text { estudantes em vários países, bem como em } \\
\text { diferentes subgrupos demográficos de cada } \\
\text { país (OCDE, 2016). (p. 19) }\end{array}$ & $\begin{array}{l}\text { A BNCC integra a política nacional da } \\
\text { Educação Básica e vai contribuir para o } \\
\text { alinhamento de outras políticas a ações, em } \\
\text { âmbito federal, estadual e municipal, } \\
\text { referentes à formação de professores, à } \\
\text { avaliação, à elaboração de conteúdos } \\
\text { educacionais e aos critérios para a oferta de } \\
\text { infraestrutura adequada para o pleno } \\
\text { desenvolvimento da educação. }\end{array}$ \\
\hline $\begin{array}{l}\text { Objetivo em } \\
\text { Matemática }\end{array}$ & $\begin{array}{l}\text { Que o indivíduo seja letrado } \\
\text { matematicamente, o que visa descrever as } \\
\text { habilidades dos indivíduos para raciocinar } \\
\text { matematicamente e utilizar os conceitos, } \\
\text { procedimentos, fatos e ferramentas } \\
\text { matemáticos para descrever, explicar e } \\
\text { prever fenômenos. Busca analisar até que } \\
\text { ponto, estudantes dessa idade sabem lidar } \\
\text { adequadamente com a matemática ao serem } \\
\text { confrontados com certos problemas e } \\
\text { situações, a maioria apresentada em } \\
\text { contextos do mundo real. }\end{array}$ & $\begin{array}{l}\text { Espera-se que os alunos desenvolvam a } \\
\text { capacidade de identificar oportunidades de } \\
\text { utilização da matemática para resolver } \\
\text { problemas, aplicando } \\
\text { procedimentos e resultados para obter } \\
\text { soluções e interpretá-las segundo os } \\
\text { contextos das situações. E também } \\
\text { desenvolver o letramento matemático } \\
\text { através dos processos matemáticos e } \\
\text { habilidades. }\end{array}$ \\
\hline
\end{tabular}

Fonte: os autores com base em Brasil (2016) e Brasil (2017b) 
A nova BNCC, traz um conjunto de aprendizagens essenciais que os alunos devem construir até o final da educação obrigatória, ou seja, a Educação Básica. Ela busca contribuir em vários aspectos para com as políticas educacionais, destacamos aqui a avaliação e o desenvolvimento da Educação.

O PISA procura avaliar o desempenho e habilidades adquiridas pelos alunos ao final da educação obrigatória e busca o desenvolvimento de um conjunto de informações para monitorar o desenvolvimento de conhecimentos e habilidades dos educandos, bem como monitorar os sistemas educacionais ao longo do tempo. Sendo assim os objetivos estão ligados pois a base procura desenvolver a aprendizagem através de habilidades e competências já o PISA procura avaliar o desenvolvimento dessas habilidades e competências.

Para o objetivo específico em Matemática, é aparente a relação entre eles, ambos os documentos buscam trabalhar com o letramento matemático, de forma que os indivíduos possam pensar matematicamente para resolver problemas envolvidos no contexto real. Quando a BNCC menciona o letramento matemático, como um compromisso a ser desenvolvido, elenca em nota de rodapé a Matriz do PISA 2012, com a definição completa de letramento matemático.

Em seguida o documento da base, traz as expressões "competências" e "habilidades" que devem ser desenvolvidas através dos processos matemáticos, afirma que "esses processos de aprendizagem são potencialmente ricos para o desenvolvimento de competências fundamentais para o letramento matemático (raciocínio, representação, comunicação e argumentação)" (BRASIL, 2017b, p. 264). Embora a BNCC faça referência ao PISA somente no letramento matemático, os processos matemáticos, competências e habilidades também são elencadas no documento do PISA, fazendo parte do modelo do letramento matemático.

Na tabela 2, trouxemos as relações evidenciadas entre a BNCC e o PISA nas definições de letramento matemáticos, processos matemáticos e habilidades/ competências. Nesta mesma tabela relacionamos os contextos e os conteúdos matemáticos que também acompanham o modelo de um letramento matemático proposto pelo PISA, mas que também é mencionado na BNCC. 
Quadro 2: Letramento matemático: definição, processos e habilidades, relações entre PISA e BNCC

\begin{tabular}{|c|c|c|}
\hline & PISA & BNCC \\
\hline $\begin{array}{l}\text { Definição } \\
\text { Letramento } \\
\text { Matemático }\end{array}$ & $\begin{array}{l}\text { Letramento matemático é a capacidade de } \\
\text { formular, empregar e interpretar a } \\
\text { matemática em uma série de contextos, o } \\
\text { que inclui raciocinar matematicamente e } \\
\text { utilizar conceitos, procedimentos, fatos e } \\
\text { ferramentas matemáticos para descrever, } \\
\text { explicar e prever fenômenos. Isso ajuda os } \\
\text { indivíduos a reconhecer o papel que a } \\
\text { matemática desempenha no mundo e faz } \\
\text { com que cidadãos construtivos, engajados } \\
\text { e reflexivos possam fazer julgamentos bem } \\
\text { fundamentados e tomar as decisões } \\
\text { necessárias. }\end{array}$ & $\begin{array}{l}\text { Definido como as competências e habilidades } \\
\text { de raciocinar, representar, comunicar e } \\
\text { argumentar matematicamente, de modo a } \\
\text { favorecer o estabelecimento de conjecturas, a } \\
\text { formulação e a resolução de problemas em uma } \\
\text { variedade de contextos, utilizando conceitos, } \\
\text { procedimentos, fatos e ferramentas } \\
\text { matemáticas. É também o letramento } \\
\text { matemático que assegura aos alunos reconhecer } \\
\text { que os conhecimentos matemáticos são } \\
\text { fundamentais para a compreensão e a atuação } \\
\text { no mundo e perceber o caráter de jogo } \\
\text { intelectual da matemática, como aspecto que } \\
\text { favorece o desenvolvimento do raciocínio lógico } \\
\text { e crítico, estimula a investigação e pode ser } \\
\text { prazeroso }\end{array}$ \\
\hline Processos & $\begin{array}{l}\text { Formular, Empregar e Interpretar. Os } \\
\text { processos matemáticos que descrevem o } \\
\text { que as pessoas fazem para conectar o } \\
\text { contexto de um problema com a } \\
\text { matemática e, dessa maneira, resolver o } \\
\text { problema, através desses processos o } \\
\text { indivíduo pode ser letrado } \\
\text { matematicamente. São atribuídos da } \\
\text { seguinte forma: } \\
\rightarrow \text { Formular situações matematicamente; } \\
\rightarrow \text { Empregar conceitos, fatos, } \\
\text { procedimentos e raciocínios matemáticos; } \\
\text { e } \\
\rightarrow \text { Interpretar, aplicar e avaliar resultados } \\
\text { matemáticos. }\end{array}$ & $\begin{array}{l}\text { Servem como estratégia para a aprendizagem } \\
\text { de resolução de problemas, de investigação, de } \\
\text { desenvolvimento de projetos e da modelagem. } \\
\text { Esses processos de aprendizagem são } \\
\text { potencialmente ricos para o desenvolvimento } \\
\text { de competências fundamentais para o } \\
\text { letramento matemático (raciocínio, } \\
\text { representação, comunicação e argumentação) e } \\
\text { para o desenvolvimento do pensamento } \\
\text { computacional. }\end{array}$ \\
\hline $\begin{array}{l}\text { Habilidades/ } \\
\text { Competências }\end{array}$ & 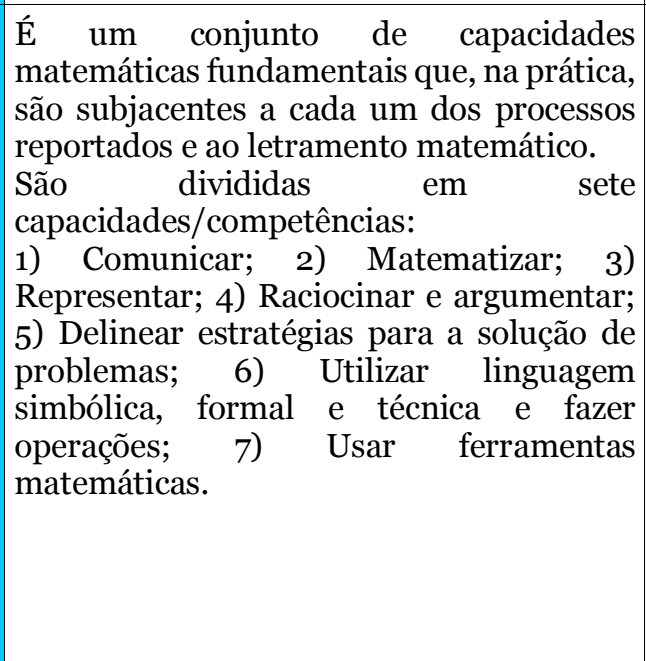 & $\begin{array}{l}\text { Competências específica é definida como a } \\
\text { mobilização de conhecimentos, habilidades, } \\
\text { atitudes e valores para resolver demandas } \\
\text { complexas da vida cotidiana, do pleno exercício } \\
\text { da cidadania e do mundo do trabalho. Para } \\
\text { Matemática são divididas em: } \\
\text { 1) Reconhecer que a Matemática é uma ciência } \\
\text { humana; 2) Desenvolver o raciocínio lógico, 3) } \\
\text { Compreender as relações entre conceitos e } \\
\text { procedimentos dos campos da Matemática; 4) } \\
\text { Fazer observações sistemáticas de aspectos } \\
\text { presentes nas práticas sociais e culturais; 5) } \\
\text { Utilizar processos e ferramentas matemáticas; } \\
\text { 6) Enfrentar situações-problema em múltiplos } \\
\text { contextos; 7) Desenvolver e/ou discutir projetos } \\
\text { de questões de urgência social; 8) Interagir com } \\
\text { seus pares de forma cooperativa }\end{array}$ \\
\hline Contextos & Pessoal, Ocupacional, Social e científico. & $\begin{array}{l}\text { Intelectual, física, afetiva, social, ética, moral e } \\
\text { simbólica. }\end{array}$ \\
\hline $\begin{array}{l}\text { Conteúdos } \\
\text { Matemáticos }\end{array}$ & $\begin{array}{l}\text { Mudanças e relações, espaços e forma, } \\
\text { quantidade, incertezas e dados. }\end{array}$ & $\begin{array}{l}\text { Números, Álgebra, Geometria, Grandezas e } \\
\text { Medidas, Estatística e Probabilidade }\end{array}$ \\
\hline
\end{tabular}

Fonte: os autores com base em Brasil (2016) e Brasil (2017b)

Como elencado na tabela 2, o letramento matemático é proposto nos dois documentos 
e abordam a mesma definição: a resolução de problemas em uma série de contextos, onde o aluno deve utilizar conceitos, procedimentos, fatos e ferramentas matemáticas reconhecendo a importância que a matemática desenvolve no mundo. Algumas palavras pautadas nas definições são diferentes, mas dentro do contexto, o significado da definição para letramento aponta o mesmo sentido dentre as frases.

O PISA 2015 apresenta um diagrama com o modelo para o letramento matemático, ele não é adicionado na BNCC, mas os elementos do diagrama como mostra a figura 1 , simplifica a definição de letramento matemático, condizendo também com o que a BNCC propõe.

Figura 1: Modelo de letramento Matemático

\section{Problema em um contexto do mundo real}

Categorias de conteúdos matemáticos: mudanças e relaçōes; espaço e forma; quantidade; incerteza e dados.

Categorias de contextos: pessoal, ocupacional, social, científico.

\section{Pensamento e ação matemática}

Conceitos matemáticos, conhecimentos e habilidades.

Capacidades fundamentais da matemática: comunicar; "matematizar"; representar; raciocinar e argumentar; delinear estratégias para a solução de problemas; utilizar linguagem simbólica, formal e técnica e fazer operaçōes; usar ferramentas matemáticas.

Processos: formular, empregar, interpretar/avaliar.

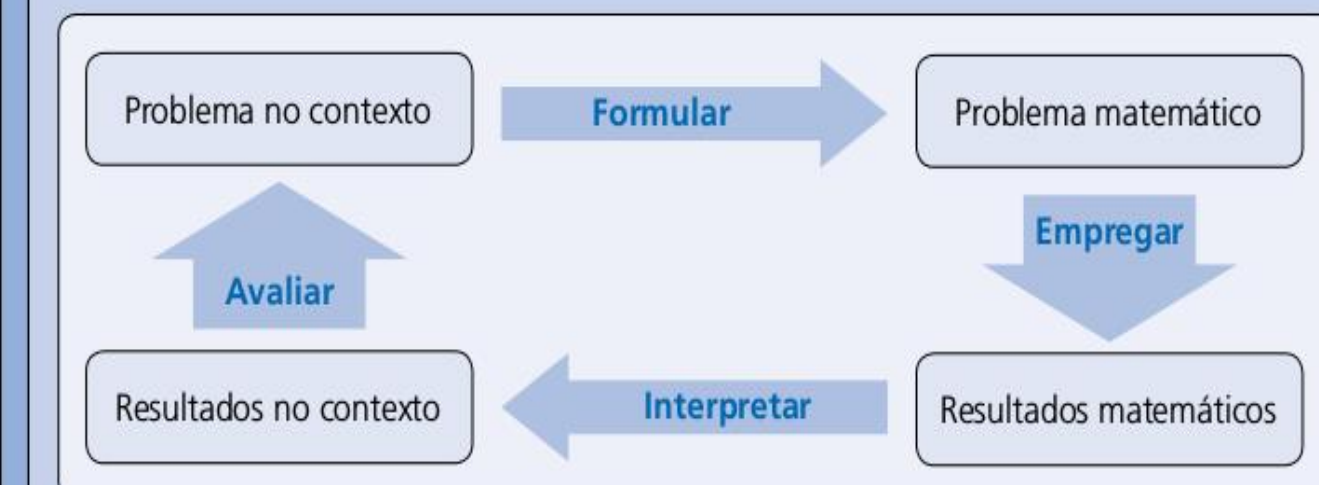

Fonte: OCDE (2016), PISA 2015 Assessment and Analytical Framework: Science, Reading, Mathematic and Financial Literacy.

Observando o modelo de letramento matemático é possível evidenciar os elementos que o constitui, e verificar que são os mesmos que especificamos na tabela 2. Os processos matemáticos são referenciados nos dois documentos, entretanto são utilizadas palavras ISSN 2526-2882 
diferenciadas na definição. No documento referente ao PISA 2015 as palavras "formular", "empregar" e "interpretar" citadas na definição de letramento, são a estrutura que organizam os processos matemáticos. É através dos processos matemáticos que os alunos conseguem resolver os problemas envolvidos no contexto, conectando-os com a Matemática. Os processos matemáticos como estrutura para o letramento matemático é um ciclo, nele a palavra "formular" se refere a habilidade do aluno ao ler o problema contextualizado, tentar identificar a matemática e estrutura que utilizará para a resolução. A palavra "empregar" contida nos processos matemáticos busca desenvolver o raciocínio matemático, através de fatos e procedimentos, ampliando o conhecimento matemático já construído pelo aluno, para poder assim, resolver o problema já formulado. Por fim a palavra "interpretar" diz respeito a competência de o aluno refletir sobre a solução do problema, interpretando-o e avaliando o problema no contexto real (BRASIL, 2016). Segundo o PISA somente através desses processos que o sujeito pode ser letrado matematicamente.

A BNCC em sua abordagem sobre os processos matemáticos traz como estrutura para o processo matemático as palavras: raciocinar, representar, comunicar e argumentar matematicamente. A Base não traz a definição de cada um desses processos como o PISA, apenas afirma que esses processos são potencialmente valorosos para o desenvolvimento de competências essenciais para o letramento matemático (BRASIL, 2017b). Entendemos que para a definição desses processos referentes à Base, o aluno ao ler o problema contextualizado terá que primeiramente raciocinar matematicamente, buscando modelos para a resolução, em seguida representar o problema matematicamente com os conceitos já produzidos anteriormente pelo aluno. O comunicar e argumentar matematicamente seria o estabelecer uma ligação entre o contexto real contido no problema juntamente com a matemática e tirar conclusões sobre o problema resolvido.

Vale destacar que quando a BNCC aborda os processos matemáticos, os mesmos não aparecem referenciados com o PISA, entretanto é notável a relação entre os conceitos sobre processos matemáticos, que também estão interligados. Destacamos ainda que as palavras utilizadas na Base para processos matemáticos estão presentes no PISA na parte de competências/capacidades fundamentais, presentes também na tabela 2.

Assim para as habilidades/competências em Matemática, a BNCC busca desenvolver no aluno competências específicas. Para a Base a competência é definida como a "mobilização de conhecimentos (conceitos e procedimentos), habilidades (práticas, cognitivas e socioemocionais), atitudes e valores para resolver demandas complexas da vida cotidiana, do pleno exercício da cidadania e do mundo do trabalho" (BRASIL, 2017b, p. 8). O PISA apresenta as capacidades fundamentais que também estão relacionadas aos processos matemáticos, entretanto essas capacidades no documento também são denominadas de "competências" que 
são ferramentas para o desenvolvimento matemático. O PISA apresenta 7 competências fundamentais e a BNCC elenca 8 competências, como mostra a tabela 2. No PISA essas competências fundamentais estão relacionadas ao letramento e para elementos fundamentais que os alunos precisam para resolução de problemas no contexto do real. Na Base as competências em Matemática, também está focalizada nos conhecimentos essenciais que os educandos precisam para a resolução de problemas envolvida no contexto cultural, social, histórico e tecnológico necessários para o letramento matemático. Entretanto também é colocado nas competências da Base a necessidade de trabalhar com equidade e igualdade que são temas de urgência social, este seria o único tópico listado nas competências e habilidades que deve ser desenvolvidos com os alunos, que não está relacionado com as capacidades fundamentais proposta no PISA, entretanto é um objetivo da OCDE e outros órgãos internacionais.

Outro tópico em comum que listamos na tabela 2, são os contextos envolvidos nos documentos, no PISA o contexto é "considerado um aspecto da resolução de problemas que impõe novas exigências ao solucionador (BRASIL, 2016, p. 148)”, sendo assim os contextos utilizados para categorizar a avaliação são: pessoal, ocupacional, social e científico. O PISA salienta que cada uma delas "tem de contribuir substancialmente para a mensuração do letramento matemático" (BRASIL, 2016, p. 149).

Portanto, a BNCC busca desenvolver essas condições de forma geral para todas as disciplinas, não somente em matemática, pois destaca que a "educação tem um compromisso com a formação e o desenvolvimento humano global, em suas dimensões intelectual, física, afetiva, social, ética, moral e simbólica” (BRASIL,2017a, p.16).

Há ainda os conteúdos matemáticos, que no PISA estão associados a quatro categorias os conteúdos: mudanças e relações, espaços e forma, quantidade, incertezas e dados. Na BNCC, os conteúdos estão também relacionados a formulação das habilidades e competências: Números, Álgebra, Geometria, Grandezas e Medidas, Estatística e Probabilidade. Os conteúdos não aparecem diferenciados por séries. Na Tabela 3 apresentamos o que cada conteúdo busca desenvolver, tanto no PISA quanto na BNCC. 
Quadro 3: Categorias de conteúdos PISA e BNCC

\begin{tabular}{|c|c|c|}
\hline & \multicolumn{2}{|c|}{ Série de categorias de conteúdos } \\
\hline \multirow{4}{*}{ PISA } & Mudanças e relações & $\begin{array}{l}\text { Matematicamente, isso significa modelar essas } \\
\text { mudanças e relações com funções e equações } \\
\text { apropriadas, bem como criar, interpretar e traduzir as } \\
\text { diversas representações de relações gráficas e simbólicas. }\end{array}$ \\
\hline & Espaços e forma & $\begin{array}{l}\text { Nessa área envolve a geometria, mas também utiliza-se de } \\
\text { recursos de outras áreas matemáticas, como visualização } \\
\text { espacial, medida e álgebra. }\end{array}$ \\
\hline & Quantidade & $\begin{array}{l}\text { É necessário compreender medidas, contas, grandezas, } \\
\text { unidades, indicadores, tamanhos relativos e tendências e } \\
\text { padrões numéricos. Aspectos do raciocínio quantitativo, } \\
\text { como a percepção dos números, a compreensão da } \\
\text { múltipla representação de números, o requinte no cálculo } \\
\text { mental e computacional. }\end{array}$ \\
\hline & Incertezas e dados & $\begin{array}{l}\text { É trabalhado dados estatísticos, probabilísticos, o } \\
\text { conhecimento de números e de aspectos da álgebra, como } \\
\text { gráficos e representações simbólicas. Inclui identificar o } \\
\text { lugar da variação nos processos, com a percepção da } \\
\text { quantificação dessa variação, do reconhecimento da } \\
\text { incerteza, do erro na medição e do conhecimento das } \\
\text { probabilidades. }\end{array}$ \\
\hline \multirow{5}{*}{ BNCC } & Números & $\begin{array}{l}\text { Aproximação, proporcionalidade, equivalência e ordem, } \\
\text { noções fundamentais da Matemática. Deve ser proposto, } \\
\text { por meio de situações significativas, sucessivas } \\
\text { ampliações dos campos numéricos. No estudo desses } \\
\text { campos numéricos, devem ser enfatizados registros, usos, } \\
\text { significados e operações. }\end{array}$ \\
\hline & Álgebra & $\begin{array}{l}\text { Busca estudar equivalência, variação, interdependência e } \\
\text { proporcionalidade. Em síntese, essa unidade temática } \\
\text { deve enfatizar o desenvolvimento de uma linguagem, o } \\
\text { estabelecimento de generalizações, a análise da } \\
\text { interdependência de grandezas e a resolução de } \\
\text { problemas por meio de equações ou inequações. }\end{array}$ \\
\hline & Geometria & $\begin{array}{l}\text { Tem por objetivos, estudar posição e deslocamentos no } \\
\text { espaço, formas e relações entre elementos de figuras } \\
\text { planas e espaciais pode desenvolver o pensamento } \\
\text { geométrico dos alunos. }\end{array}$ \\
\hline & Grandezas e medidas & $\begin{array}{l}\text { Estudo das medidas e das relações métricas entre elas, } \\
\text { grandezas e escalas. Contribui ainda para a consolidação } \\
\text { e ampliação da noção de número, a aplicação de noções } \\
\text { geométricas e a construção do pensamento algébrico. }\end{array}$ \\
\hline & $\begin{array}{c}\text { Estatística e } \\
\text { probabilidade }\end{array}$ & $\begin{array}{l}\text { Busca desenvolver habilidades para coletar, organizar, } \\
\text { representar, interpretar e analisar dados em uma } \\
\text { variedade de contextos, de maneira a fazer julgamentos } \\
\text { bem fundamentados e tomar as decisões adequadas. Isso } \\
\text { inclui raciocinar e utilizar conceitos, representações e } \\
\text { índices estatísticos para descrever, explicar e predizer } \\
\text { fenômenos. }\end{array}$ \\
\hline
\end{tabular}

Fonte: os autores com base em Brasil (2016) e Brasil (2017b)

Com base no que cada conteúdo propõe como indicativo para se trabalhar e avaliar, ao 
compará-los traçamos as seguintes relações entre os documentos, listada na Tabela 4.

Quadro 4: Comparativo entre os temas em matemática - PISA 2015 e BNCC

\begin{tabular}{|c|c|}
\hline PISA & BNCC \\
\hline Quantidade & Números \\
\hline Incerteza e dados & Estatística e Probabilidade \\
\hline Espaço e forma & Geometria \\
\hline Mudanças e relações & Álgebra \\
\hline Sem associação & Grandezas de medidas \\
\hline
\end{tabular}

Fonte: os autores

Os conteúdos fundamentais cobrados em ambos os documentos, diferem em algumas características básicas, entretanto ambos visam o desenvolvimento da aprendizagem matemática do educando, em especial o PISA procura também avaliar esses conhecimentos que devem ser adquiridos pelo aluno, juntamente com a capacidade de aplicá-los no contexto real.

Buscamos nesta análise evidenciar as relações que permeiam os documentos do PISA e a BNCC. Podemos destacar que "é possível observar uma forte relação entre os objetivos de aprendizagem da BNCC e as avaliações unificadas. Fica-se com a impressão de que as habilidades que estão na Base de Matemática são descrições de itens de avaliação em larga escala" (ABRALE, 2017, p.1).

Antunes (2017) retrata que "tanto para o governo quanto para o setor empresarial é fundamental um alinhamento com as diretrizes do Pisa, os países que têm destaque nessa avaliação são classificados pela OCDE como aqueles que investem numa educação de qualidade e terão mão de obra qualificada, o que possibilita a atração de investimento externo" (ANTUNES, 2017, p.1).

Após as considerações apresentadas acima por meio de estudo comparativo entre o PISA e a nova Base (Matemática), fica ainda alguns os questionamentos: será que estruturar uma Base Nacional Comum, relacionado com as avaliações em larga escala trará mais oportunidades e investimentos externos para o país? Ou será que a estruturação da Base relacionada ao PISA, melhorará o desempenho em dos alunos em Matemática, e aumentará o nível educacional brasileiro nos rankings das avaliações externas e em larga escala?

\section{Considerações Finais}

No presente artigo tivemos como objetivo comparar os documentos oficiais do PISA e da BNCC de Matemática, evidenciando e discutindo as definições, processos, letramento, habilidades e conteúdos estruturantes, abordados nos documentos. A pesquisa documental foi ISSN 2526-2882 
apresentada através da análise desses documentos.

Apresentamos também os reflexos das avaliações em larga escala no processo de ensino-aprendizagem, principalmente em matemática onde nem sempre os resultados são satisfatórios e esperados, reforçando mais uma vez o formalismo matemático, ainda tão empregada nas nossas salas de aula. Além disso o artigo retratou um breve histórico do sistema educacional brasileiro até a implementação da Base Nacional Comum Curricular, bem como relatamos o início das aplicações das avaliações externas e em larga escala no Brasil, trazendo como foco o PISA.

Ao analisar a Matriz do PISA 2015 e a BNCC do Ensino Fundamental, apontamos a influência que as avaliações externas e em larga escala exercem nas políticas públicas educacionais. Portanto pudemos evidenciar as relações presentes nas definições, objetivos, competências e habilidades, bem como nos processos para um letramento matemático que compõem também os contextos e conteúdos dispostos nos documentos.

Por mais que o PISA e a Base, busquem desenvolver e avaliar a aprendizagem do aluno, bem como primar pela qualidade do sistema educacional, destacamos que, deve haver uma ainda um grande investimento na formação e preparação do professor e toda comunidade escolar. Destacamos ainda que antes da construção e implementação de qualquer reforma e estruturação do ensino, os sujeitos envolvidos diretamente nesse processo, precisam dar as suas contribuições efetivas, para que isso não fique apenas no discurso da democracia. Afinal de contas, o centro do ensino é o aluno, e as preocupações para uma boa educação deve estar voltada primeiramente para eles e não apenas para rankings ou economia do país. A BNCC foi homologada e o PISA é aplicado a cada três anos, mas cabe ao professor, que está vivendo a realidade em sala de aula, repensar nas estratégias de ensino e métodos, que devem ser em especial, voltados para as necessidades de aprendizagem do aluno. Vale refletirmos ainda que é direito do aluno desenvolver seu cognitivo para ser letrado matematicamente, mas o ensino que deve envolver o letramento matemático deve ir além dos resultados e metas que são exigidos internamente e externamente.

Temos ainda um grande processo pela frente para que isso se efetive de fato, e este, deve envolver principalmente a formação de professores inicial e continuada, mas esse é um assunto para um próximo artigo!

\section{Referências}

ABRALE, ASSOCIAÇÃO BRASILEIRA DOS AUTORES DE LIVROS EDUCATIVOS (Brasil) (Ed.). Ranqueamento internacional e sua influência na BNCC. 2017. Disponível em: <http://www.abrale.com.br/ranqueamento-internacional-e-suainfluencia-na-bncc/>. Acesso em: 20 junho. 2018. 
AGUIAR, M. A. S. da. Relato da resistência à instituição da BNCC pelo conselho nacional de educação mediante pedido de vista e declarações de votos. In: AGUIAR, M. A; DOURADO, L. F. A BNCC na contramão do PNE 2014-2024: avaliação e perspectivas. [Livro Eletrônico]. - Recife: ANPAE, 2018. p. 8-22.

ANTUNES, A. Fiocruz - Fundação Oswaldo Cruz. A quem interessa a BNCC? 2017. Disponível em: <http://www.epsjv.fiocruz.br/noticias/reportagem/a-queminteressa-a-bncc >. Acessoem 17. julho. 2018

BAUER, A.; ALAVARSE, O.M.; OLIVEIRA, R.P. Avaliação em larga escala: uma sistematização do debate. Educação e Pesquisa, São Paulo, v. 41, n. especial, p. 1.367-1.382, 2015. Disponível em: < HYPERLINK "http://www.scielo.br/pdf/ep/v41nspe/1517-9702ep-41-spe-1367.pdf"http://www.scielo.br/pdf/ep/v41nspe/1517-9702-ep-41-spe1367.pdf>, acesso em: 05. julho. 2018

BRASIL. Brasil no PISA 2015: análises e reflexões sobre o desempenho dos estudantes brasileiros / OCDE-Organização para a Cooperação e Desenvolvimento Econômico. - São Paulo: Fundação Santillana, 2016.

BRASIL. Instituto Nacional de Estudos e Pesquisas Educacionais Anísio Teixeira. PISA 2015. Disponível em: <http://portal.inep.gov.br/pisa>. Acesso em: 12. Julho. 2018.

BRASIL. Instituto Nacional de Estudos e Pesquisas Educacionais Anísio Teixeira. Saeb. 2017a Disponível em: <http://portal.inep.gov.br/saeb>. Acesso em: 12. Julho. 2018.

BRASIL. Lei no. 9.394, de 20 de dezembro de 1996. Estabelece as diretrizes e bases da educação nacional. Brasília, DF, 1996. Disponível em: < HYPERLINK "http://legis.senado.leg.br/legislacao/ListaPublicacoes.action?id=102480\&tipoDoc umento=LEI\&tipoTexto=PUB"http://legis.senado.leg.br/legislacao/ListaPublicacoe s.actionid=102480\&tipoDocumento=LEI\&tipoTexto $=$ PUB $>$ acesso em fevereiro de 2019.

BRASIL. Ministério da Educação. Governo Federal. Base Nacional Curricular Comum (BNCC). 2017b Disponível em: <http://basenacionalcomum.mec.gov.br/abase/>. Acesso em: 06. Maio. 2018.

BRASIL. Secretaria de Educação Fundamental. Parâmetros curriculares nacionais: introdução aos parâmetros curriculares nacionais / Secretaria de Educação Fundamental. - Brasília: MEC/SEF, 1997. 126.

BOGDAN, R.; BIKLEN, S. Investigação qualitativa em Educação: uma introdução à teoria e aos métodos. Portugal: Porto Editora, 1994.

BURIASCO, R. L. C. e SOARES, M. T. C. Avaliação de sistemas escolares: da classificação dos alunos à perspectiva de análise de sua produção matemática. In: VALENTE, W. R. (org.). Avaliação em matemática: histórias e perspectivas atuais. $2 a$ ed. 
Campinas: Papirus, 2012. p. 101-142.

CNTE. A reforma do ensino médio suprime direitos, privatiza a educação e terceiriza os/as trabalhadores/as escolares. Revista Retratos da Escola, Brasília, v. 11, n. 20, p. 337-343, jan./jun. 2017.

COLA, André Ricardo. Avaliação externa e em larga escala: o entendimento de professores que ensinam matemática na educação básica. 2015. $93 \mathrm{f}$. Dissertação (Mestrado em Educação Matemática) - Faculdade de Ciências Exatas e Tecnologia, Pontifícia Universidade Católica de São Paulo, São Paulo, 2015.

FERNANDES, D. Avaliar para aprender: fundamentos, práticas e políticas. São Paulo: Unesp, 2009. 221 p.

FONSECA, J. J. S. Metodologia da pesquisa científica. Fortaleza: UEC, 2002. Apostila. Disponível em <http://leg.ufpi.br/subsiteFiles/lapnex/arquivos/files/ApostilaMETODOLOGIA_DA_PESQUISA\%281\%29.pdf> Acesso em: 17. Julho. 2018.

GABRIEL, F. A.; PEREIRA, A. L.; SKEIKA, T. A filosofia da práxis e o papel dos intelectuais orgânicos no processo de constituição da hegemonia da classe trabalhadora segundo Gramsci. Revista Linhas. No prelo.

GATTI, B. Avaliação: contexto, história e perspectivas. Olhares, Guarulhos, v. 2, n. 1, p. 8-26, maio 2014.

GIL, A.C. Como classificar as pesquisas. In: Gil, A.C. Como elaborar projetos de pesquisa. São Paulo: Athas; 2006. p. 41-58.

HELDER, R. R. Como fazer análise documental. Porto, Universidade de Algarve, 2006.

HORTA NETO, João Luiz. As avaliações externas e seus efeitos sobre as políticas educacionais: uma análise comparada entre a União e os estados de Minas Gerais e São Paulo. Tese (Doutorado em Política Social) Universidade de Brasília, Brasília, 2013.

IMPA, 10 Questões para Professores de Matemática... e como o PISA Pode Ajudar a Respondê-las. $1^{0}$ edição, 2018. Disponível em: < https://www.sbm.org.br/wpcontent/uploads/2018/o2/Livro_Dez_Questoes-PISA_2018.pdf>, Acesso em: 12. Julho. 2018.

LINO, L. A. As ameaças da reforma desqualificação e exclusão. Revista Retratos da Escola, Brasília, v. 11, n. 20, p. 75-90, jan./jun. 2017. Disponível em: $<$ http//www.esforce.org.br>. Acesso em Fevereiro de 2019

MAINARDES, J. As relações entre Currículo, Pedagogia e Avaliação no Contexto das Avaliações de Sistemas Educacionais. In: BAUER, A.; GATTI, B. A.. (Org.). Ciclo de debates: vinte e cinco anos de avaliação de sistemas educacionais no 
Brasil - implicações nas redes de ensino, no currículo e na formação de professores- v. 2. 'ed. Florianopolis: Insular, 2013, v. 1, p. 179-191.

OCDE. PISA 2015 Assessment and Analytical Framework: Science, Reading, Mathematic and Financial Literacy. Paris: OCDE Publishing, 2016.

PEREZ, T. BNCC - a Base Nacional Comum Curricular na prática da gestão escolar e pedagógica. São Paulo: Editora Moderna, 2018.

SÁ-SILVA, J.R.; ALMEIDA, C.D.; GUINDANE, J.F. Pesquisa documental: pistas teóricas e metodológicas. Revista Brasileira de História \& Ciências Sociais, v.1, n.1, p.115, 2009.

SILVA, Mariana C. V. Avaliação em larga escala de alunos com necessidades educacionais especiais no município de Londrina - PR. 2012. $140 \mathrm{f}$. Dissertação (Mestrado em Educação) - Universidade Estadual de Londrina, Londrina, 2013.

SOARES, M. BERNARDO, N. 20 anos da LDB: como a lei mudou a Educação. Revista Nova Escola, 2016. Disponível em $<$ HYPERLINK "https://novaescola.org.br/conteudo/4693/20-anos-ldb-darcy-ribeiro-avancosdesafios-linha-do-tempo"https://novaescola.org.br/conteudo/4693/20-anos-ldbdarcy-ribeiro-avancos-desafios-linha-do-tempo>. Acesso em: 09. Julho. 2018.

SOUZA, E. P. de. A história da educação brasileira: breve histórico das reformas sofridas durante o regime militar. XIII Congresso Nacional de Educação EDUCERE, Curitiba, 2017. Disponível em: < HYPERLINK "http://educere.bruc.com.br/arquivo/pdf2017/26721_13292.pdf"http://educere.br uc.com.br/arquivo/pdf2017/26721_13292.pdf> , Acesso em: 12. Julho. 2018.

STECHER, Brian M. Consequences of large-scale, high-stakes testing on school and classroom practice. In: HAMILTON, Laura; STECHER, Brian M.; KLEIN, Stephen P. (Ed.). Making sense of test-based accountability in education. Santa Monica: Rand,2002. p. 79-100.

UNESCO. Organização das Nações Unidas para a Educação, a Ciência e a Cultura. Os desafios do ensino de matemática na educação básica. - Brasília: UNESCO; São Carlos: EdUFSCar, 2016. 114.p.

VERDE, P. L. Base Nacional Comum: desconstrução de discursos hegemônicos sobre currículo mínimo. NUPEAT-IESA-UFG, v.5, n.1, Jan./Jun.,p. 78-97, Artigo 84. Dossiê ECOTRANSD: Ecologia dos saberes e Transdisciplinaridade, 2015.

WILKINS, S. L. Princípios e propostas sobre o conhecimento matemático nas avaliações externas. 2013. 136 f. Dissertação (Mestrado) - Faculdade de Filosofia, Ciências e Letras de Ribeirão Preto, Universidade de São Paulo, São Paulo, 2013. 
ZANARDINI, J. B. Ontologia e Avaliação da Educação Básica no Brasil (1990- 2007). 2008. 209f. Tese (Doutorado em Educação) - Programa de pós-graduação em Educação, Centro de Ciências da Educação, Universidade Federal de Santa Catarina, Florianópolis, 2008.

\section{Biografia Resumida}

Emilly Gonzales Jolandek: Licenciada em Matemática (2018) pela Universidade Estadual de Ponta Grossa (UEPG). Mestranda no programa de Pós-Graduação em Ensino de Ciências e Educação Matemática pela UEPG. Pós-Graduanda em Educação: métodos e técnicas de ensino pela Universidade Tecnológica Federal do Paraná (UTFPR). Docente de apoio pedagógico de Matemática no Colégio Marista Maringá.

Link Lattes: http://lattes.cnpq.br/5085381393473869

Contato: emillyjolandek@gmail.com

Ana Lúcia Pereira: Doutora (2011) e Mestre (2005) em Ensino de Ciências e Educação Matemática pela Universidade Estadual de Londrina (UEL). Graduada em Ciências e Matemática na Universidade do Norte Pioneiro (UENP, 1994). Professora do Departamento de Matemática e Estatística da Universidade Estadual de Ponta Grossa (UEPG, Brasil) desde 2012. Professora do Programa de Pós-Graduação em Educação, em que serviu como vice-coordenador (2014-2015) e do Programa em Ensino de Ciências e Educação Matemática (2017) na Universidade Estadual de Ponta Grossa. É membro do Banco de Avaliadores do Sistema Nacional de Avaliação da Educação Superior - BASis - INEP/MEC. Foi pesquisadora visitante na University of Strathclyde, no Reino Unido (2016-2018) pelo Programas Estratégicos - DRI, com apoio da Capes. Também atuou como coordenadora Institucional do Programa de Bolsas de Iniciação à Docência (PIBID / Capes / UEPG, 2012-2013) e como Coordenadora de Gestão e Processos Educacionais no PIBID (Capes / UEPG, 2014-2016). Foi Chefe do Núcleo Regional de 
Educação de Jacareziho no Estado do Paraná (2009-2010). Presidente do Sindicato dos Professores (APP) da região Jacarezinho (2002-2009). Autor de vários artigos em revistas e atua como referee nas áreas de Políticas Educacionais, Formação de Professores; Práticas e Desenvolvimento Curricular; Ensino e Aprendizagem; Psicanálise; Midias Socias; Ciência, Tecnologia e Sociedade e Educação Matemática. Editor associado da Frontiers in Psicologia da Educação desde 2015. Bolsista de Produtividade da Fundação Araucária-Paraná.

Link Lattes: http://lattes.cnpq.br/4341211442617752

Contato: anabaccon@uepg.br.

Luiz Otávio Rodrigues Mendes: Licenciado em Matemática (2017) pela Universidade Estadual de Ponta Grossa (UEPG). Mestre em Ensino de Ciências e Educação Matemática pela UEPG. Doutorando no programa de Pós-Graduação em Educação para a Ciência e a Matemática, pela Universidade Estadual de Maringá (UEM). Pós-Graduado em Educação Inclusiva (2018) pela Faculdade Educacional da Lapa (FAEL). Agradecimento a CAPES pela bolsa do doutorado.

Link Lattes: http://lattes.cnpq.br/8661805143319375

Contato: mendesluizotavio@hotmail.com 